\title{
Jobs and Research-Related Outcomes from the NIST-ARRA Construction Grants
}

\author{
Michael D. Walsh \\ National Institute of Standards and Technology, \\ Gaithersburg, MD 20899 \\ michael.walsh@nist.gov
}

In 2009 and 2010, NIST's Construction Grant Program (NCGP) issued grants to 15 universities and 1 nonprofit institution to construct new or expand existing research facilities. Using $\$ 180$ million provided by the American Recovery and Reinvestment Act (ARRA) and an additional \$221 million provided by awardees, these grants led to the construction of 87,991 square meters (947,000 square feet) of academic research and development (R\&D) space. This amounted to approximately $10 \%$ of all R\&D space constructed by U.S. academic institutions during the same period. This paper summarizes these 16 construction grants and highlights the number of additional research grants, patents, publications, and other benefits that resulted from the use of these facilities, six years after ARRA was signed into law.

Key words: ARRA; construction grants; impact; research facilities.

Accepted: August 24, 2016

Published: August 26, 2016

http://dx.doi.org/10.6028/jres.121.018

\section{Introduction}

The American Recovery and Reinvestment Act (ARRA) (Public Law 111-5) which was signed into law in February of 2009, appropriated more than $\$ 840$ billion in Federal funds to support a variety of programs that were designed to create jobs and promote economic activity through investments in areas such as education, healthcare, infrastructure, and energy production [1]. As part of this effort, the National Institute of Standards and Technology (NIST) received \$180 million to fund major scientific building construction projects at U.S. institutions of higher education and non-profit research institutions through NIST's Construction Grant Program (NCGP).

NCGP was initially authorized and funded under the Consolidated Appropriations Act (Public Law 110-161) of 2008. Under this program, NIST awarded grants to colleges, universities, and other non-profit science research institutions to construct new or expand existing research facilities (e.g., laboratories, test facilities, measurement facilities, research computing facilities, observatories, etc.) In May of 2008, NIST announced that \$24 million would be awarded in the first NCGP competition. Under this competition, grants were awarded through a highly competitive selection process in which a team of experts reviewed and ranked proposals according to an established set of selection criteria. These criteria included 1) the scientific and technical merit of the proposed use of the facility, 2) the need for federal funding, 3) the quality of the design of the research facility, and 4) the adequacy of the project management plan. On November 24, 2008, NIST announced that 3 of the 93 proposals submitted to the 2008 competition were chosen to receive construction grants [2].

Once the availability of ARRA funds was announced in January of 2009, NIST immediately made plans to run another NCGP competition. The new NIST-ARRA competition added three additional criteria to the selection process: 1 ) projects selected had to complement one or more programs of the Department of Commerce's three science organizations (i.e., NIST, the National Oceanic and Atmospheric Administration [NOAA], and the National Telecommunications and Information Administration [NTIA]); 2) projects had 
to preserve jobs, promote economic recovery, spur technological advances, and develop infrastructure to provide long-term economic benefits; and 3) projects had to be "shovel-ready" meaning that at the time of the award, they would be at an advanced stage of development where work could begin immediately. In an effort to accelerate the selection process, NIST requested to use up to $\$ 60$ million of ARRA construction grant funds to fund four meritorious proposals from the 2008 NCGP competition that also met the ARRA selection criteria. Upon receiving approval, NIST announced the first awards for NIST-ARRA grants on July 20, 2009. These grants included: [3]

- \$15 million to the University of Miami for the Marine Technology and Life Sciences Seawater Research Building;

- \$14.4 million to Auburn University for the Center for Advanced Science, Innovation and Commerce;

- \$11.1 million to Rice University for the new Brockman Hall for Physics; and

- \$15 million to the University of North Carolina Wilmington for a new marine biotechnology facility.

In May of 2009, NIST announced a second NCGP competition for the remaining \$124 million in ARRA construction grant funds. On January 8, 2010, after all proposals were reviewed and assessed, NIST announced that 11 universities and 1 non-profit research organization were selected to receive the next round of construction grants [4]. These grants included:

- \$15 million to the University of Pittsburgh for new nanoscience and experimental physics laboratories;

- \$15 million to Nova Southeastern University Inc. for the Center of Excellence for Coral Reef Ecosystem Science research facility;

- \$12.4 million to the University of Maine for the Advanced Nanocomposites in Renewable Energy Laboratory;

- \$12.3 million to the University of Kansas Center for Research, Inc. for the Measurement, Materials and Sustainable Environment Center;

- \$11.8 million to the University of Kentucky for the expansion of the Center for Applied Energy Research Laboratory;

- \$11.8 million to Purdue University for the Center for High Performance Buildings at the Ray W. Herrick Laboratories;

- \$11.6 million to the Georgia Tech Research Corporation for the Carbon-Neutral Energy Solutions Laboratory;

- $\$ 10.3$ million to the University of Maryland for an advanced quantum science laboratory in the school's new Physical Sciences Complex;

- $\$ 8.1$ million to the Woods Hole Oceanographic Institution for a new laboratory for Ocean Sensors and Observing Systems;

- $\$ 6.9$ million to the University of Nebraska for the Nanoscience Metrology Facility;

- \$6.9 million to Georgetown University for the Institute for Soft Matter Synthesis and Metrology; and

- \$1.4 million to Columbia University for an ultraclean geochemistry laboratory at the LamontDoherty Earth Observatory.

Although cost sharing was not a requirement, each NIST-ARRA awardee made significant financial contributions to support their construction projects. The total amount of funds provided by awardees amounted to $\$ 221$ million. This raised the total amount of funds invested in the construction of new research facilities to $\$ 400$ million with $45 \%$ provided by ARRA funds and $55 \%$ provided by awardees.

This report summarizes the new facilities constructed under these 16 NIST-ARRA grants and based on a survey of awardees, highlights the number of research grants, patents, publications, and other benefits that resulted from the use of these new facilities by 2015, six years after ARRA was signed into law. 


\section{Construction Jobs Created}

Most construction grant awardees began finalizing plans for construction activities within a month after grants were announced. These activities included efforts to finalize architectural and engineering plans, obtain regulatory approvals and permits, and arrange for numerous other administrative activities associated with large capital improvement projects. Actual construction activities began in the first quarter of 2010 and continued through the last quarter of 2013. The average construction time for a project receiving a NIST-ARRA grant was two years and four months.

One of the conditions for an ARRA grant required each awardee to provide a quarterly report of the number of jobs created by their grant. Awardees estimated the number of jobs they created by converting the number of hours worked by full and part time employees into an estimate of full-time equivalent employees [5]. Figure 1 shows the number of jobs created between 2010 and 2013 for all of the NISTARRA awardees. The number of construction jobs created per quarter peaked in the second quarter of 2012 when 421 jobs were reported. Between the time when construction began on the first NIST-ARRA project until the time when construction ended on the last, a total of 3,733 full-time equivalent construction jobs were created.

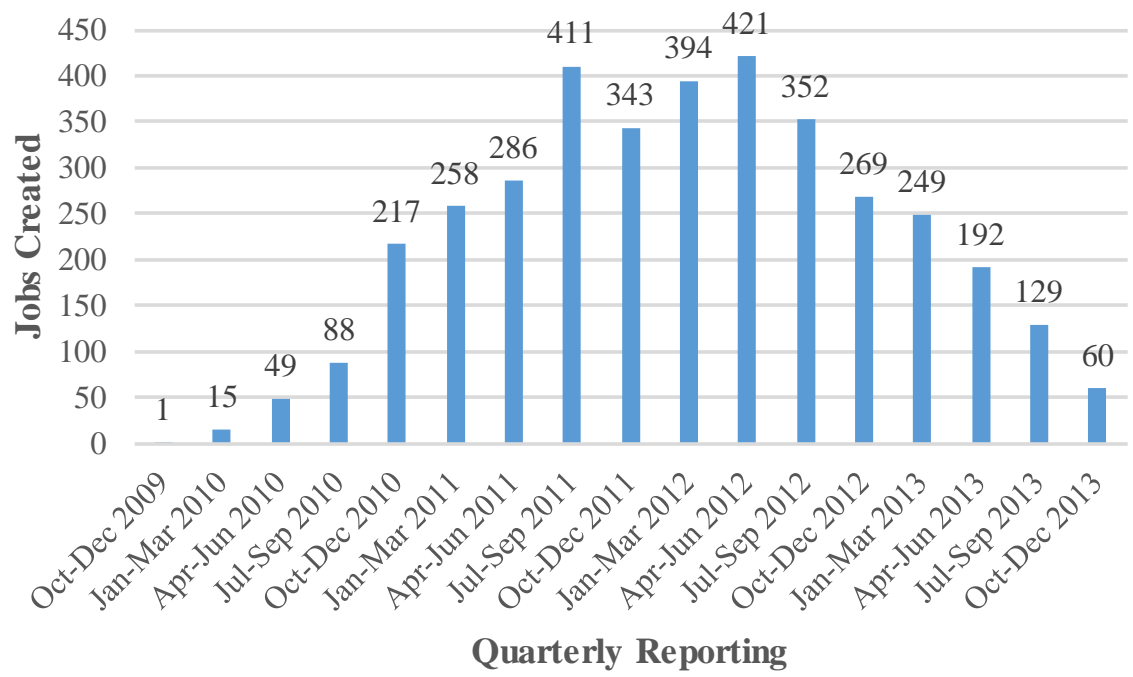

Fig. 1. Number of full-time equivalent, construction jobs created by the 16 NIST-ARRA construction grants.

Once all construction projects were completed, NIST-ARRA grants added 87,991 square meters (947,130 square feet) of new R\&D research space with an average 5,499 square meters (59,196 square feet) per awardee. During the same time period, total new R\&D space constructed for all U.S. academic institutions amounted to 891,869 square meters (9,600,000 square feet), with an average of 4,383 square meters (47,183 square feet) per institution [6]. Therefore, during this time period, NIST-ARRA grants contributed approximately $10 \%$ of the total new R\&D research space constructed by U.S. academic institutions.

\section{Predominant Research Areas}

To illustrate the nature of the facilities selected for construction, NIST-ARRA grants have been grouped into four categories that correspond to the predominant research areas described by awardees in their proposals. These categories include Advanced Materials and Technology Research, Energy Development Research, Environmental Science Research, and Physics Research. Figure 2 shows the predominant research areas and the amount of funding received by the 16 NIST-ARRA awardees. 


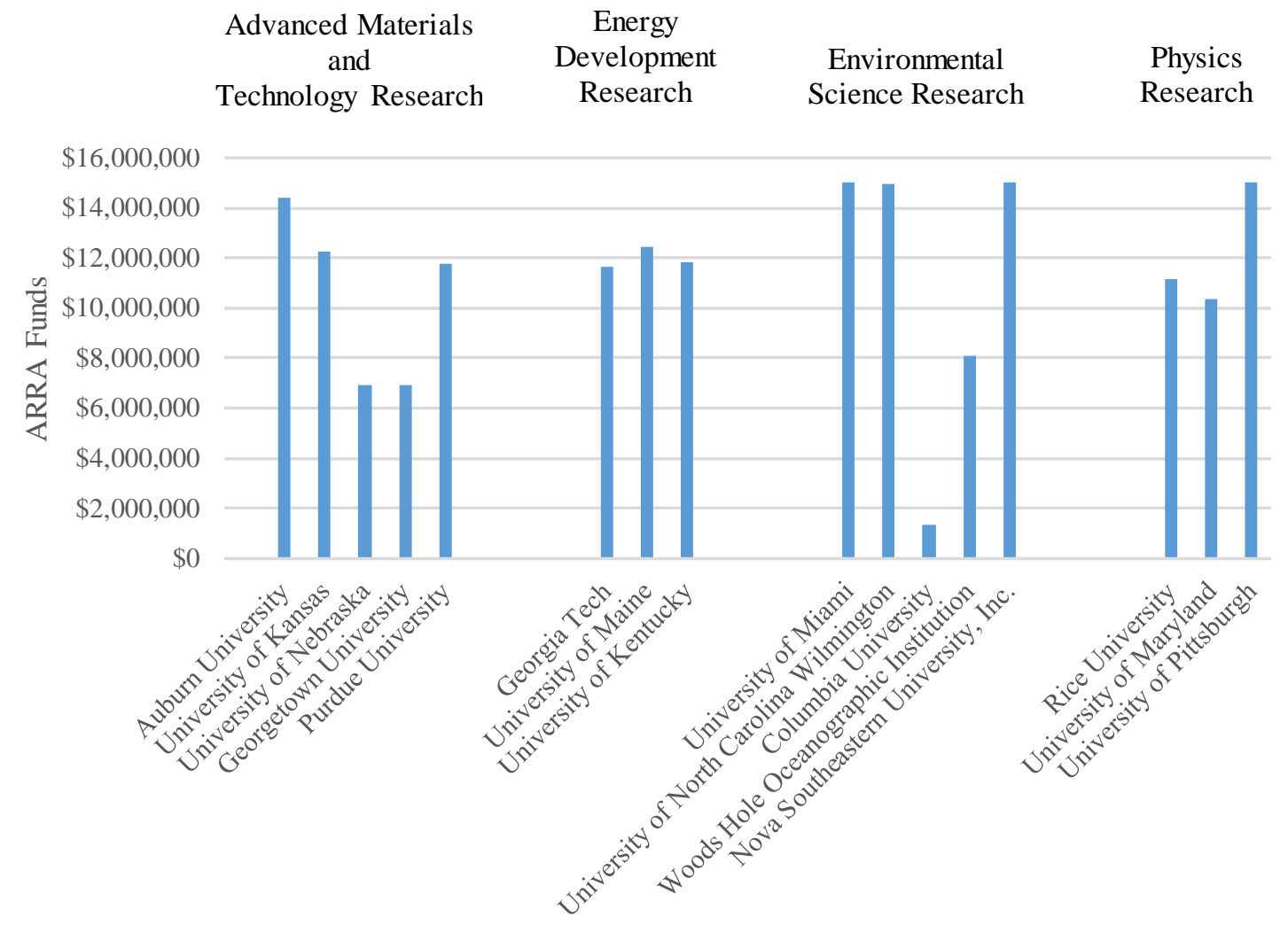

Fig. 2. NIST-ARRA funding by awardees and predominant research areas.

\subsection{Advanced Materials \& Technology Research}

Five of NIST-ARRA construction grants support research in advanced materials and technology development. This includes, for example, the characterization and properties of materials as well as bioinformatics, genomics, food safety research, and building technologies. Awardees in this category include Auburn University, the University of Kansas, the University of Nebraska, Georgetown University, and Purdue University. The total amount of NIST-ARRA funds for these five grants was $\$ 52.2$ million which amounts to $29 \%$ of the total amount of NIST-ARRA funds available. Awardees provided an additional \$88.4 million to support related construction, which brings the total amount of funds invested in this area to $\$ 140.7$ million. This led to the creation of 33,231 square meters (357,690 square feet) of space primarily dedicated to advanced materials and technology research.

\subsubsection{Auburn University}

In July of 2009, Auburn University, located in Auburn, Alabama, received a \$14.4 million NISTARRA grant to construct the Center of Advanced Science, Innovation, and Commerce (CASIC). CASIC was designed to provide state-of-the-art computational resources and research facilities to support a wide range of research activities in the fields of agriculture, engineering, science and mathematics, forestry, wildlife sciences, architecture, design, and construction [7]. The university raised an additional \$14.4 million from the State of Alabama bringing the total investment of the new facility to \$28.9 million.

This new 6,317 square meter (68,000 square foot) facility provides space for 20 new laboratories supporting research in, for example, food safety, aquaculture development and sustainability, water and environmental quality, information science, and biofuel/bioenergy technologies. CASIC allows researchers from different fields access to state-of-the-art research equipment including a supercomputer, a mass array 
spectrometer, multiple sequencers, deionized and purified water systems, and other lab support equipment and storage space.

By May of 2015, Auburn University reported that the new facility allowed them to hire 4 additional full-time faculty members, and support research programs that led to 39 new research grants totaling $\$ 7.8$ million, 10 patent applications, and 112 research publications.

\subsubsection{The University of Kansas Center for Research, Inc.}

In January of 2010, the University of Kansas Center for Research, Inc. (KUCR), located in Lawrence, Kansas, received a \$12.3 million NIST-ARRA grant to construct the Measurement, Materials, and Sustainable Environment Center (M2SEC). KUCR is a not-for-profit research foundation that operates under the administrative jurisdiction of the University of Kansas Office of Research. M2SEC was designed to provide space for engineers and scientists researching projects in energy, transportation, global climate change, composite materials technology, and sustainable building practices [8]. The foundation raised an additional \$6.5 million to support construction of the center bringing the total investment to \$18.8 million.

This new 3,223 square meter (34,690 square foot) facility houses a variety of bioengineering, environmental, and infrastructure-related research laboratories. Current research projects involve biofuels production, characterization and emissions, remote sensing technologies used to monitor the movements of glaciers and ice sheets, commercial avionics improvements, advanced materials fracture and fatigue research, and advanced sustainable building material evaluation. The M2SEC facilities include reflected sunlight for illumination, solar shadings for temperature control, and a "green" roof to support carbon sequestration and insulation. The new building also includes an anechoic chamber that is used to study polar regions and climate change, a fracture and fatigue lab that is used to test the strength of materials (aircraft wings, bridges, etc.) in three dimensions, and equipment to study gene expression analysis and biofuel production.

By May of 2015, the University of Kansas reported that the new facility allowed them to hired 6 additional full-time faculty members and support research programs that led to 36 new research grants totaling \$13.3 million, 10 patent applications, 8 patents, and 95 research publications.

\subsubsection{The University of Nebraska}

In January of 2010, the University of Nebraska, located in Lincoln, Nebraska, received a \$6.9 million NIST-ARRA grant to construct the Nanoscience Metrology Facility. This new facility was designed to provide accessible, state-of-the-art laboratories and shared research facilities to support research in nanotechnology and materials science [9]. The University raised an additional \$6.9 million to support construction bringing the total investment of the new facility to $\$ 13.8$ million.

This new 2,971 square meter (32,000 square foot) facility is a temperature-stabilized, low-vibration, low electromagnetic field building that houses a nanofabrication cleanroom and materials preparation facility, as well as laboratories for nanofiber characterization, manufacturing metrology, and nanophotonics. The facility provides researchers with access to electron microscopy, scanning probe microscopy, X-ray materials characterization, and crystallography labs. The nanofabrication facility also contains an IS07 certified 372 square meter (4,000 square foot) cleanroom that enables film deposition, characterization, and optical and electron-beam lithography for the production of complex nanoscale structures and devices. The Electron Microscopy Facility houses several transmission and scanning microscopes including a high-resolution transmission electron microscope.

By May of 2015, the University of Nebraska reported that the new facility allowed them to hire 17 additional faculty members in a variety of fields including physics and astronomy, biomolecular engineering, chemistry, chemical engineering, mechanical and materials engineering, and electrical engineering. The new facility also supported research programs that led to several large interdisciplinary grants, 91 patent applications, and 9 patents. 


\subsubsection{Georgetown University}

In January of 2010, Georgetown University, located in Washington, D.C., received a \$6.9 million NIST-ARRA grant to construct the Institute for Soft Matter Synthesis and Metrology, I(SM $)^{2}$. The I(SM $)^{2}$ facility was designed to support research into fundamental principles of soft matter and the development of practical measurement tools that can be applied to soft matter synthesis, precision measurement, and characterization of materials [10]. Georgetown raised an additional \$48.8 million to support the project, bringing the total investment of the new facility to $\$ 55.7$ million.

This new 14,400 square meter (155,000 square foot) facility supports research in materials that are neither traditional liquids nor solids, such as liquid crystals, gels, colloids, polymers, foams, granular matter and many biological materials. Soft matter research plays a critical role in the development of new technologies, materials, and products. The new facility provides the necessary environmental controls for the sensitive measurement technologies needed for soft matter research and enables the expansion of ongoing soft matter research by scientists at Georgetown, NIST, and other regional institutions.

By May of 2015, Georgetown University reported that the new facility allowed them to hire 10 additional full-time faculty members and support research programs that led to 42 new research grants totaling \$15.4 million.

\subsubsection{Purdue University}

In January of 2010, Purdue University, located in West Lafayette, Indiana, received an \$11.8 million NIST-ARRA grant to construct the Center for High Performance Buildings (CHPB) at the Ray W. Herrick Laboratories. CHPB was designed to support Purdue's mission to partner with industry in the development, demonstration, evaluation, and deployment of new technologies and analytical tools for high performance buildings [11]. Purdue raised an additional \$11.8 million to support the project, bringing the total investment of the new facility to $\$ 23.5$ million.

This new 6,317 square meter (68,000 square foot) building contains research laboratories that are designed to test and troubleshoot energy-efficient, automated environmental control strategies and to provide the data required to generate, validate, and improve predictive technologies for designers of buildings. The facilities include two psychrometric chamber laboratories that are used to simulate indoor and outdoor conditions to study the performance of heating and cooling equipment. Other simulation labs are available to study HVAC and refrigeration technologies.

By May of 2015, Purdue University reported that the new facility allowed them to hire 3 additional fulltime faculty members and support research programs that led to 6 patent applications, 6 patents, and 175 research papers.

\subsection{Energy Development Research}

Three NIST-ARRA construction grants support research in energy development. This includes, for example, research in clean and renewable energy, biofuels, carbon capture, solar energy, and wind energy. Awardees in this category include Georgia Tech, the University of Maine, and the University of Kentucky. The total amount of NIST-ARRA funds awarded to these three universities was \$35.9 million. Awardees provided an additional $\$ 18.5$ million to support related construction, which brings the total amount of funds invested to $\$ 54.4$ million. This led to the creation of 10,312 square meters (111,000 square feet) of new energy development research space.

\subsubsection{Georgia Tech Research Corporation}

In January of 2010, the Georgia Tech Research Corporation, located in Atlanta, Georgia, received an \$11.6 million NIST-ARRA grant to construct Georgia Tech's new Carbon-Neutral Energy Solutions Laboratory (CNES). CNES was designed to foster industry collaboration and support translational and precommercial research in clean, low carbon energy technologies [12]. An additional \$11.6 million was raised by the university to bring the total investment of the new laboratory to $\$ 23.3$ million. 
This new 4,181 square meter (45,000 square foot) facility accommodates a diverse range of science and technology experts engaged in advanced clean energy research. Research efforts are focused on the development and commercialization of technologies involving carbon capture, biofuels, gas purification, solar energy, and other solutions for the oil, gas, and chemical industries.

By May of 2015, Georgia Tech reported that the new facility allowed them to hire 4 additional faculty members and support research that led to 5 patent applications, 1 patent, and 5 research papers.

\subsubsection{The University of Maine}

In January of 2010, the University of Maine located in Orono, Maine, received a \$12.4 million NISTARRA grant for the construction of the Advanced Nanocomposites in Renewable Energy Laboratory (ANREL). The ANREL facility was designed to support the development of offshore wind technologies [13]. The university raised an additional \$3 million to support the project, bringing the total investment of the new facility to $\$ 15.4$ million.

The 2,787 square meter (30,000 square foot) laboratory supports designing, prototyping, and testing of large structural hybrid composite and nanocomposite components for use in the deep water, offshore wind energy industry. This highly unique facility complements ongoing research at NIST involving advanced materials, nanomaterials, and nanocomposites.

By May of 2015, the University of Maine reported that the new facility allowed them to hire 19 additional full-time faculty members and support research programs that led to 52 new research grants totaling \$35 million, 3 patent applications, and 60 research papers.

\subsubsection{The University of Kentucky}

In January of 2010, the University of Kentucky, located in Lexington, Kentucky, received an $\$ 11.8$ million NIST-ARRA grant to construct an expansion of the university's Center for Applied Energy Research (CAER) laboratory. Established 30 years ago, the CAER laboratory is a multidisciplinary research center that focuses on energy-related developments. The new CAER facility supports research in areas such as coal processing, fuel use, coal combustion byproducts, engineered fuels, derivation of addedvalue materials and chemicals, and renewable energy such as biofuels and bioenergy, electrochemistry, solar energy, and environmental remediation [14]. The university raised an additional \$3.9 million, bringing the total investment of the expansion to $\$ 15.8$ million.

The new 3,345 square meter (36,000 square foot) facility includes labs for process development, prototype manufacturing and testing as well as applied research on batteries, capacitors, solar energy materials, and biofuels. The facility also includes a 186 square meter (2,000 square foot) dry lab that is used for battery manufacturing and development.

By May of 2015, the University of Kentucky reported that the new facility allowed them to hire 4 additional full-time faculty members and support research programs that led to 38 new research grants totaling \$15.5 million, 10 patent applications, and 8 patents.

\subsection{Environmental Science Research}

Five of the ARRA construction grants support research in environmental sciences. This includes, for example, marine life and coral reef research, climate research, coastal and deep ocean monitoring, and hurricane research. Awardees in this category include the University of Miami, the University of North Carolina at Wilmington, Columbia University, Woods Hole Oceanographic Institution, and Nova Southeastern University. The total amount of ARRA funds for these five grants was \$54.4 million. Awardees provided an additional $\$ 62.7$ million to support related construction, bringing the total amount of funds invested to $\$ 117.2$ million. This led to the creation of 25,775 square meters (277,440 square feet) of new environmental science research space. 


\subsubsection{The University of Miami}

In July of 2009, the University of Miami, located in Miami, Florida, received a \$15 million NISTARRA grant for the construction of the Marine Technology Life Sciences Seawater (MTLSS) research building. MTLSS provides a dedicated research facility for the study of marine animals, the connections between oceans and human health, and the impacts of climate change on marine organisms and ecosystems [15]. The university raised an additional $\$ 28.8$ million, bringing the total investment of the new building to $\$ 43.8$ million.

The new 9,290 square meter (100,000 square foot) MTLSS building accommodates advanced research involving coral reefs, aquaculture, fisheries, and marine ecosystems. The building houses 12 individual research laboratories, the Surge Structure-Atmosphere Interaction Research Facility (SUSTAIN), the Marine Life Sciences Center, and the National Resource for Aplysia facility. SUSTAIN is a shared-use facility equipped with a single 1,600 horsepower fan. This fan generates winds equivalent to a category 5 hurricane, allowing researchers to study the physics and dynamics of landfall hurricanes as well as the impacts of severe wind-driven and wave-induced storm surges on coastal structures. The Marine Life Sciences Center is currently being used by researchers to study the impact on marine life resulting from the Deep Water Horizon Oil spill. The National Resource for Aplysia facility provides high-quality, laboratory cultured Aplysia (sea slugs) for biomedical researchers throughout the world.

By May of 2015, the University of Miami reported that the new facility has allowed them to hire 13 additional full-time faculty members and support research programs that led to 6 new research grants totaling \$34 million.

\subsubsection{The University of North Carolina at Wilmington}

In July of 2009, the University of North Carolina at Wilmington (UNCW), located in Wilmington, North Carolina, received a \$15 million NIST-ARRA grant for the construction of a new marine biotechnology facility. The new facility houses UNCW's Marine Biotechnology in North Carolina (MARBIONC) program whose mission is to stimulate economic development in North Carolina through the discovery, development, and marketing of new products and technologies derived from living organisms found in the sea [16]. The university raised an additional \$15 million bringing the total investment of the new building to $\$ 30$ million.

This new 6,410 square meter (69,000 square foot) facility includes state-of-the-art instrumentation that allows for on-site testing and analytical services. The building was specifically designed to promote collaborative activities between academic, private, and public-sector research organizations and offers opportunities for companies to lease laboratory space.

By May of 2015, UNCW reported that the new facility allowed them to obtain 5 new research grants totaling \$5.3 million and support research programs that led to 4 patents and 31 research papers.

\subsubsection{Columbia University}

In January of 2010, Columbia University, located in New York City, received a \$1.4 million NISTARRA grant to construct an expansion of their Ultraclean Geochemistry Laboratory at the Lamont-Doherty Earth Observatory. The Lamont-Doherty Earth Observatory mission is to seek fundamental knowledge about the origin, evolution, and future of the natural world [17]. The Ultraclean Geochemistry Laboratory expansion and improvement was designed to double the capacity of the existing laboratory space that is devoted to the study of global climate processes. The university raised an additional \$1.4 million to support the project, bringing the total investment of the new facility to $\$ 2.7$ million.

This new 130 square meter (1,400 square foot) Ultraclean Geochemistry Laboratory enables researchers to study a variety of climate systems, deep ocean currents, and other ocean circulation processes. Studying global climate processes requires environmental samples to be handled in extremely clean laboratories in order to minimize the risk of contamination. The Ultraclean Geochemistry Laboratory provides state-of-the art systems to handle air quality, temperature, and humidity with high precision. 


\subsubsection{Woods Hole Oceanographic Institution}

In January of 2010, Woods Hole Oceanographic Institution (WHOI), a non-profit research institution located in Woods Hole, Massachusetts, received an \$8.1 million NIST-ARRA grant for the construction of the new Laboratory for Ocean Sensors and Observing Systems (LOSOS) [18]. The Woods Hole Oceanographic Institution is dedicated to advancing the understanding of the ocean and its interaction with other earth systems. The institution raised an additional \$2 million to support the project, bringing the total investment of the new facility to $\$ 10.1$ million.

This new 1,951 square meter (21,000 square foot) facility is an interdisciplinary research center for scientists and engineers developing the next generation of sensor technologies for ocean observation. The LOSOS facility is being used to build networks of sensors that will collect long-term ocean and sea-floor data over several years. The facility includes a 353 square meter (3,800 square foot) area for assembly and maintenance of buoys, mooring assemblies, and other equipment for sea-floor instrumentation, along with instrumentation and electronics test and prep labs.

LOSOS currently supports three major oceanographic projects: 1) the Ocean Observatories Initiative, a major program funded by the National Science Foundation (NSF) to build networks of sensors to collect long-term ocean and sea-floor data over several years, 2) the Martha's Vineyard Coastal Observatory, a combination undersea instrument platform and shore-based observation facility developed by WHOI to provide a unique, real-time, coastal ocean monitoring station in the New England region, and 3) the Ocean Bottom Seismometer Instrument Pool, a program funded by the NSF to build, maintain, and operate a pool of advanced sea-floor seismometers for use by NSF-funded researchers. WHOI is one of three institutions responsible for developing, maintaining, and operating such instruments. The LOSOS facility also supports collaborative work with NOAA in ocean observing, climate studies, weather observing, and earthquake and tsunami research.

\subsubsection{Nova Southeastern University Inc.}

In January of 2010, Nova Southeastern University Inc., located in Fort Lauderdale, Florida, received a \$15 million NIST-ARRA grant for the construction of the Center of Excellence for Coral Reef Ecosystem Science Research Facility. The new facility is a multi-disciplinary research facility that generates information and research products to help understand, conserve, and protect coral reef ecosystems [19]. The university raised an additional $\$ 15.6$ million to support the project, bringing the total investment of the new facility to $\$ 30.6$ million.

This new 7,990 square meter (86,000 square foot) expansion allows researchers to study the history and environmental conditions of coral reefs, the effects of climate change and pollution, and the ability of coral reefs to recover from injury and damage. The facility includes wet labs for microbiology and genomics research, geology-style labs for sclerochronology, electronics labs for ocean hydrodynamics, computational labs for geospatial analysis and mapping, and a marina and scuba diving facility at Port Everglades. Funding also enabled the replacement of a seawall system with a new overwater experimentation area.

By May of 2015, Nova Southeastern University reported that the new facility allowed them to hire 5 additional faculty members and support research programs that led to 47 new research grants totaling $\$ 3.7$ million.

\subsection{Physics Research}

Three of the NIST-ARRA grants support advanced physics research. This includes, for example, research in magnetic and superconducting compounds, nonequilibrium dynamics, quantum science, condensed matter physics, nanoscience, and high-energy physics. Awardees in this category include Rice University, the University of Maryland, and the University of Pittsburgh. The total amount of ARRA funds for these three grants was \$36.5 million. Awardees provided an additional \$51.3 million to support related construction, which brings the total amount of funds invested in this category to $\$ 87.8$ million. This led to the creation of 19,138 square meters (206,000 square feet) of advanced physics research space. 


\subsubsection{Rice University}

In July of 2009, Rice University, located in Houston, Texas, received an \$11.1 million NIST-ARRA grant to construct Brockman Hall for Physics [20]. Brockman Hall was specifically designed to consolidate and update research laboratories within the Department of Physics and Astronomy. Rice University raised an additional \$33.4 million to support the project, bringing the total investment of the new facility to $\$ 44.5$ million.

The new 10,219 square meter (110,000 square foot) facility includes 16 physics labs and 6 engineering labs that have state-of-the art vibration, noise, temperature, humidity, and air-flow controls that support high-precision measurements used in atomic, molecular, and optical physics, biophysics, condensed matter physics, nanoengineering, and photonics research. Since completion, the facility has supported a variety of research projects in magnetic and superconducting compounds, nonequilibrium dynamics of ultracold lithium atoms, green chemistry, energy sustainability, and computer security.

By May of 2015, Rice University reported that the new facility allowed them to hire 7 additional fulltime researchers and support research programs that led to 45 new research grants totaling more than $\$ 43.8$ million, 63 patent applications, 42 patents, and 407 research publications.

\subsubsection{The University of Maryland}

In January of 2010, the University of Maryland, located in College Park, Maryland, received a \$10.3 million NIST-ARRA grant to construct the Laboratory for Advanced Quantum Science (LAQS). LAQS supports research in atomic, molecular and optical physics, condensed matter physics, and quantum information science [21]. With the receipt of this grant, the university was able to raise an additional $\$ 5.2$ million to support the project, bringing the total investment of the new facility to $\$ 15.5$ million.

LAQS is a 1,951 square meter (21,000 square foot) state-of-the-art laboratory for researchers working at the forefront of quantum science. The new facility includes advanced, ultralow vibration, temperature, and relative humidity controls, as well as a modular design that separates noise- and heat-generating equipment and sensitive experiments.

By May of 2015, the University of Maryland reported that the new facility allowed them to hire two additional faculty researchers and support research that led to a National Science Foundation Physics Frontier Center grant, a cooperative agreement with the Army Research Laboratory, and a partnership with Lockheed Martin for a quantum engineering center.

\subsubsection{The University of Pittsburgh}

In January of 2010, the University of Pittsburgh, located in Pittsburgh, Pennsylvania, received a \$15 million NIST-ARRA grant to construct 13 new, state-of-the-art, experimental physics laboratories in the Department of Physics and Astronomy. The new facility was designed to provide infrastructural support for the university's Nanoscience and Technology Initiative [22]. The university was able to raise an additional \$12.8 million to support the project, bringing the total investment of the new laboratories to \$27.8 million.

The new 2,508 square meters (27,000 square feet) of laboratory space, combined with upgrades to an additional 3,995 square meters (43,000 square feet) of existing space has significantly increased the university's capacity to pursue research involving new scientific measurement technologies, novel electronic and telecommunication devices, and large-scale storms and hurricanes. With this new space, the university created two new research centers: the Pittsburgh Quantum Institute that supports physics, chemistry, and engineering faculty; and the Science Education Research Center that supports faculty from nine natural science departments within the Dietrich School of Arts and Sciences.

By May of 2015, the University of Pittsburgh reported that the new facility allowed them to hire 12 additional full-time faculty members, and support research programs that led to 34 new research grants totaling \$28 million, 4 patents, and 58 research publications. 


\section{Summary}

In 2009 and 2010, NCGP issued 16 NIST-ARRA construction grants to 15 universities and 1 nonprofit institution to construct new or expand existing R\&D facilities. Allocating \$180 million of Federal funds along with \$221 million in funds from awardees, the NIST-ARRA grants directed more than \$400 million to develop 87,991 square meters (947,130 square feet) of academic R\&D space. This created 3,733 new construction jobs and accounted for approximately $10 \%$ of R\&D space constructed by all U.S. academic institutions during the same time period.

By modernizing facilities and providing space to install state-of-the-art laboratories and equipment, NIST-ARRA grants significantly expanded opportunities for academic researchers to engage in highly innovative R\&D projects. As of May of 2015, 11 of the 16 awardees reported that their new facilities helped obtain 349 new research grants totaling more than $\$ 235$ million in R\&D funding. This amount is $\$ 97$ million more than the total amount of NIST-ARRA funds received by these 11 awardees and $\$ 49$ million more than the total amount they provided. Fourteen of the awardees reported that they were able to hire an additional 114 researchers, submit more than 201 new patent applications, obtain 82 new patents, and publish more than 943 research papers.

\section{References}

[1] The Recovery Act. Available at https://www.whitehouse.gov/recovery. Accessed August 26, 2016.

[2] Baum M (November 24, 2008) NIST Awards \$24 Million in Grants for New Research Facilities Dedicated to Quantum Measurement, Marine Ecology. Available at http://www.nist.gov/public_affairs/releases/2008construction_grants.cfm. Accessed August 26, 2016.

[3] Baum M (July 20, 2009) NIST Awards \$55.5 Million in Grants for New University Research Facilities. Available at http://www.nist.gov/public_affairs/releases/20090720_cgp_awards.cfm. Accessed August 26, 2016.

[4] Baum M (January 8, 2010) NIST Awards \$123 Million in Recovery Act Grants to Construct New Research Facilities. Available at http://www.nist.gov/public_affairs/releases/20100108_cgp_awards.cfm. Accessed August 26, 2016.

[5] Data on the number of jobs created was obtained from the http://www.recovery.gov website. This website, which tracked spending and activities associated with all ARRA grants is no longer accessible.

[6] Gibbons MT (2015) Research Space at Academic Institutions Increased 4.7\% between FY 2011 and FY 2013. InfoBrief. NSF 15-316. (National Science Foundation, Arlington, VA). Available at http://www.nsf.gov/statistics/2015/nsf15316/. Accessed August 26, 2016.

[7] Hubbard CASIC Building. Available at http://www.auburnresearchpark.com/CASIC/. Accessed August 26, 2016.

[8] University of Kansas School of Engineering (2012) Engineering Research Facility Opens Doors for Discovery. Available at http://engr.ku.edu/news/2012-10-15/engineering-research-facility-opens-doors-discover. Accessed August 26, 2016.

[9] Wilbeck C (2010) UNL wins \$6.9 million grant to help fund nanoscience facility. Available at http://engineering.unl.edu/unlwins-69-million-grant-help-fund-nanoscience-facility/. Accessed August 26, 2016.

[10] Institute for Soft Matter Synthesis and Metrology. Available at https://softmatter.georgetown.edu/. Accessed August 26, 2016.

[11] Venere E (2010) Purdue creating center for high-performance buildings at Herrick Labs. Available at http://www.purdue.edu/newsroom/research/2010/100111HerrickNIST.html. Accessed August 26, 2016.

[12] Israel B (2013) Carbon-Neutral Energy Solutions Lab Unlocks the Potential of Clean Energy. Available at http://www.news.gatech.edu/2013/10/18/carbon-neutral-energy-solutions-lab-unlocks-potential-clean-energy. Accessed August 26, 2016.

[13] Dagher H (2010) UMaine Receives \$12.4 Million for Deepwater Offshore Wind Research Facility. Available at https://umaine.edu/news/blog/2010/01/08/umaine-receives-12-4-million-for-deepwater-offshore-wind-research-facility/. Accessed August 26, 2016.

[14] About CAER. Available at http://www.caer.uky.edu/about/about.shtml. Accessed August 26, 2016.

[15] Marine Technology \& Life Sciences Seawater Research Building. Available at http://yyy.rsmas.miami.edu/groups/mtlss/. Accessed August 26, 2016.

[16] MARBIONC: Marine Biotechnology in North Carolina. Available at http://uncw.edu/marbionc/. Accessed August 26, 2016.

[17] About Lamont-Doherty Earth Observatory. Available at http://www.ldeo.columbia.edu/about-ldeo. Accessed August 26, 2016.

[18] Laboratory for Ocean Sensors and Observing Systems. Available at http://www.whoi.edu/losos/home. Accessed August 26, 2016.

[19] Nova Southeastern University's Center of Excellence for Coral Reef Ecosystems Research. Available at http://nova.campusguides.com/c.php?g=112417\&p=726543. Accessed August 26, 2016.

[20] Boyd J (2011) NIST director, NASA astronaut unveil Brockman Hall for Physics. Available at http://news.rice.edu/2011/03/25/rice-dedicates-state-of-the-art-physics-research-facility/. Accessed August 26, 2016.

[21] Joint Quantum Institute (2010) Award for LAQS Labs: UMD Receives \$10.3 Million Grant for Quantum Science Labs. Available at http://jqi.umd.edu/news/award-laqs-labs. Accessed August 26, 2016. 
[22] Kelly M (2010) NIST Gives Pitt \$15 Million Grant to Expand Nanoscience, Experimental Physics Facilities. Available at https://www.chronicle.pitt.edu/story/nist-gives-pitt-15-million-grant-expand-nanoscience-experimental-physics-facilities. Accessed August 26, 2016.

About the author: Michael D. Walsh, Ph.D. is a senior economist in the Technology Partnerships Office at NIST. He is responsible for analyzing economic impacts of Federal technology transfer activities and prepares the annual technology transfer report for the Department of Commerce as well as the annual "Federal Laboratory Technology Transfer Summary Report to the President and the Congress." The National Institute of Standards and Technology is an agency of the U.S. Department of Commerce. 